\title{
Astaxanthin Protects Primary Hippocampal Neurons against Noxious Effects of $\mathbf{A} \beta$-Oligomers
}

\author{
Pedro Lobos, ${ }^{1}$ Barbara Bruna, ${ }^{1}$ Alex Cordova, ${ }^{1}$ Pablo Barattini, ${ }^{1}$ Jose Luis Galáz, \\ Tatiana Adasme, ${ }^{1}$ Cecilia Hidalgo, ${ }^{1,2}$ Pablo Muñoz, ${ }^{3}$ and Andrea Paula-Lima ${ }^{1,4}$ \\ ${ }^{1}$ Biomedical Neuroscience Institute, Faculty of Medicine, University of Chile, 8380453 Santiago, Chile \\ ${ }^{2}$ Institute of Biomedical Sciences and Center for Molecular Studies of the Cell, Faculty of Medicine, University of Chile, \\ 8380453 Santiago, Chile \\ ${ }^{3}$ Interdisciplinary Center for Innovation in Health (CIIS), School of Medicine, University of Valparaíso, 2341369 Valparaíso, Chile \\ ${ }^{4}$ Institute for Research in Dental Sciences, Faculty of Dentistry, University of Chile, 8380492 Santiago, Chile
}

Correspondence should be addressed to Andrea Paula-Lima; acpaulalima@u.uchile.cl

Received 17 October 2015; Revised 28 December 2015; Accepted 1 February 2016

Academic Editor: Christian Wozny

Copyright (C) 2016 Pedro Lobos et al. This is an open access article distributed under the Creative Commons Attribution License, which permits unrestricted use, distribution, and reproduction in any medium, provided the original work is properly cited.

\begin{abstract}
Increased reactive oxygen species (ROS) generation and the ensuing oxidative stress contribute to Alzheimer's disease pathology. We reported previously that amyloid- $\beta$ peptide oligomers $(\mathrm{A} \beta \mathrm{Os})$ produce aberrant $\mathrm{Ca}^{2+}$ signals at sublethal concentrations and decrease the expression of type- 2 ryanodine receptors (RyR2), which are crucial for hippocampal synaptic plasticity and memory. Here, we investigated whether the antioxidant agent astaxanthin (ATX) protects neurons from A $\beta$ Os-induced excessive mitochondrial ROS generation, NFATc4 activation, and RyR2 mRNA downregulation. To determine mitochondrial $\mathrm{H}_{2} \mathrm{O}_{2}$ production or NFATc4 nuclear translocation, neurons were transfected with plasmids coding for HyperMito or NFATc4-eGFP, respectively. Primary hippocampal cultures were incubated with $0.1 \mu \mathrm{M}$ ATX for $1.5 \mathrm{~h}$ prior to A $\beta$ Os addition $(500 \mathrm{nM})$. We found that incubation with ATX $(\leq 10 \mu \mathrm{M})$ for $\leq 24 \mathrm{~h}$ was nontoxic to neurons, evaluated by the live/dead assay. Preincubation with $0.1 \mu \mathrm{M}$ ATX also prevented the neuronal mitochondrial $\mathrm{H}_{2} \mathrm{O}_{2}$ generation induced within minutes of $\mathrm{A} \beta \mathrm{Os}$ addition. Longer exposures to A $\beta$ Os $(6 \mathrm{~h})$ promoted NFATc4-eGFP nuclear translocation and decreased RyR2 mRNA levels, evaluated by detection of the eGFPtagged fluorescent plasmid and qPCR, respectively. Preincubation with $0.1 \mu \mathrm{M}$ ATX prevented both effects. These results indicate that ATX protects neurons from the noxious effects of $\mathrm{A} \beta \mathrm{O}$ s on mitochondrial ROS production, NFATc 4 activation, and RyR2 gene expression downregulation.
\end{abstract}

\section{Introduction}

Accumulation and aggregation of the amyloid $\beta$ peptide $(\mathrm{A} \beta)$ cause neuronal damage and death and induce the cognitive deficits that characterize Alzheimer's disease (AD) [1]. Soluble $A \beta$ oligomers $(\mathrm{A} \beta \mathrm{Os})$ are among the different conformations of $\mathrm{A} \beta$ aggregates found in human $\mathrm{AD}$ brains; these neurotoxins bind to neurons and induce synaptic loss, microglia and astrocyte activation, and Tau hyperphosphorylation. Moreover, $\mathrm{A} \beta \mathrm{O}$ s reproduce most $\mathrm{AD}$ pathological hallmarks when injected into animal model brains $[2,3]$. The cellular and molecular mechanisms by which $\mathrm{A} \beta \mathrm{O}$ perturb normal neuronal function have been extensively investigated [4]. In this regard, the excessive generation of reactive oxygen species (ROS) produced by $\mathrm{A} \beta \mathrm{O}$ s represents an important source of neuronal damage [5]. The consequent redox imbalance generated by $\mathrm{A} \beta \mathrm{O}$ s contributes to the pathological cascade in $\mathrm{AD}$ and other neurodegenerative diseases, in which oxidative stress is a common pathological feature $[6,7]$.

Oxidative stress occurs concomitantly with the deregulation of $\mathrm{Ca}^{2+}$ signaling and of downstream $\mathrm{Ca}^{2+}$-dependent pathways induced by $A \beta O s[8,9]$; in particular, pathways downstream of N-methyl-D-aspartate (NMDA) receptors play a key role in $\mathrm{A} \beta \mathrm{O}$ s induced neurotoxicity [10-12]. Aberrant activation of NMDA receptors leads to abnormal changes in gene expression that underlie $\mathrm{A} \beta \mathrm{O}$-induced morphological and functional defects $[13,14]$. The abnormal 
NMDA receptor-mediated $\mathrm{Ca}^{2+}$ signaling induced by $\mathrm{A} \beta \mathrm{O}$ activates the protein phosphatase calcineurin, leading to downstream activation of the transcription factor NFAT [15], which promotes spine loss [11].

Astaxanthin (ATX), a red-orange carotenoid that originates the pink or red color of salmon, trout, lobster, shrimp, and other sea organisms, exhibits antioxidant, antiinflammatory, and antiapoptotic effects. Recently, ATX was shown to protect neurons in experimental models of acute injuries, chronic neurodegenerative disorders, and neurological diseases and was proposed as a beneficial strategy to treat neurological diseases [16]. Although other antioxidants, such as resveratrol, have been shown to protect neurons from injury in similar model systems [17], ATX presents many advantages compared to other antioxidants displaying protective effects. Albeit ATX has a very similar structure to that of other carotenoids such as lutein and zeaxanthin, and it has some structural differences in the arrangement of its hydroxyl groups that provide ATX with unique characteristics. Among others properties, (i) ATX has much higher antioxidant power than other members of the carotenoid family [18]; (ii) it chelates several metal ions, preventing metal ion-induced oxidative stress [19]; (iii) it has anti-inflammatory properties [18]; (iv) it crosses the blood brain barrier, allowing free access to the central nervous system [20]; (v) it acts as damper of singlet oxygen levels [21]. The combination of these properties makes ATX a very attractive candidate for use against certain diseases of the central nervous system that are caused by increases in ROS, such as superoxide anion, hydroxyl radical, and hydrogen peroxide. Consequently, ATX has been successfully used to decrease oxidative stress in elderly patients [22] and to improve neuronal function after brain ischemia [23].

Here we investigated the possible protective effects of ATX against some of the well-known deleterious effects of $\mathrm{A} \beta \mathrm{O}$ s on primary hippocampal neurons. Our results strongly suggest that ATX protects neurons from the noxious effects which $\mathrm{A} \beta \mathrm{O}$ s exert on mitochondrial ROS production, NFATc4 activation, and downregulation of RyR2 gene expression, suggesting that this natural antioxidant agent may represent a future approach to treat $\mathrm{AD}$.

\section{Experimental Procedures}

2.1. Materials. $\mathrm{A} \beta$ peptide $(\mathrm{A} \beta 1-42)$ was purchased from Bachem Inc. (Torrance, CA). ATX was extracted from Lithodes antarcticus (BIOTEX S.A., Santiago, Chile). Hexafluoro2-propanol (HFIP) was from Merck (Darmstadt, Germany) and dimethyl sulfoxide (DMSO) from Sigma-Aldrich (St. Louis, MO). TRIzol reagent, B27 supplement, Neurobasal medium, Dulbecco's modified essential medium (DMEM), Lipofectamine 2000, and the DNA binding dye SYBR green (Platinum SYBR Green qPCR SuperMix UDG) were from Invitrogen (Carlsbad, CA). The live/dead kit was from Molecular Probes (Chicago, IL), the Ambion DNA-free ${ }^{\mathrm{TM}}$ Kit from ThermoFisher Scientific (Chicago, IL), and the ImProm-II ${ }^{\mathrm{TM}}$ Reverse Transcriptase kit from Promega (Madison, WI). The pEGFP-C1 NFAT3 (NFATc4) (plasmid \#10961; full-length human NFATc4) was a gift from Dr. J. D. Molkentin (Cambridge, MA) [24]. The HyperMito plasmid was from Evrogen (Moscow, Russia). The amplification system (MX3000P) was from Stratagene (La Jolla, CA).

2.2. Preparation of $A \beta O s . \quad A \beta_{1-42}$ peptide, prepared as a dried hexafluoro-2-propanol (HFIP) film as described previously [9], was stored at $-80^{\circ} \mathrm{C}$ for up to 4 months. Prior to use, this peptide film was dissolved in sufficient sterile DMSO to make a $5 \mathrm{mM}$ stock solution. To prepare $\mathrm{A} \beta \mathrm{Os}$ as previously described $[25,26]$, the $5 \mathrm{mM}$ peptide solution was subsequently diluted to $100 \mu \mathrm{M}$ with cold phosphate buffered saline (PBS), aged overnight at $4^{\circ} \mathrm{C}$ and centrifuged at $14,000 \times \mathrm{g}$ for $10 \mathrm{~min}$ at $4^{\circ} \mathrm{C}$ to remove insoluble aggregates (protofibrils and fibrils). The supernatant containing soluble $\mathrm{A} \beta \mathrm{O}$ s was transferred to clean tubes and stored at $4^{\circ} \mathrm{C}$. Only fresh $\mathrm{A} \beta \mathrm{O}$ preparations ( 2 days-old maximum) were used in all experiments.

2.3. Primary Hippocampal Cultures. Cultures were prepared from eighteen-day-old embryos obtained from pregnant Sprague-Dawley rats as previously described [25-29]. Briefly, brains were removed and placed in a dish containing HANKS-glucose solution. Hippocampi were dissected and, after stripping away the meningeal membranes, cells were gently dissociated in HANKS-glucose solution, centrifuged, and resuspended in DMEM medium supplemented with 10\% horse serum. Dissociated hippocampal cells were plated on polylysine-coated plates and after $1 \mathrm{~h}$ DMEM was replaced by Neurobasal medium supplemented with B-27. Cultures were incubated for $15-21$ days in vitro (DIV) at $37^{\circ} \mathrm{C}$ in a humidified $5 \% \mathrm{CO}_{2}$ atmosphere prior to experimental manipulations. The resulting cultures were highly enriched in neuronal cells, identified with neuronal anti-MAP-2, with a glial content $<24 \%$ [25]. The Ethics Committee of the Faculty of Medicine, Universidad de Chile, approved the bioethical protocol of this study. All procedures were performed in accordance with the Guideline for the Care and Use of Laboratory Animals from the National Institutes of Health, USA. Animals were housed under a $12 \mathrm{~h}$ light/dark cycle in a temperature-controlled room at $24 \pm 1^{\circ} \mathrm{C}$ with free access to food and water. Animals were euthanized under deep anesthesia to avoid animal suffering at each stage of the experiment.

2.4. Cell Viability Assay. To evaluate the effect of ATX on the cell viability of cultured hippocampal neurons maintained in vitro for 14 days (14 DIV), cultures were treated for $24 \mathrm{~h}$ with different ATX concentrations $(1 \mathrm{nM}, 10 \mathrm{nM}, 100 \mathrm{nM}$, $1 \mu \mathrm{M}, 10 \mu \mathrm{M}$, and $100 \mu \mathrm{M}$ ) and cell viability was evaluated by the live/dead kit following the manufacturer's instructions as previously described [29]. Briefly, after removal of the culture, medium cells were gently washed three times with warm PBSglucose and incubated at room temperature for $30 \mathrm{~min}$ in the presence of $2 \mu \mathrm{M}$ calcein AM ester and $1 \mu \mathrm{M}$ ethidium homodimer in PBS-glucose. Live neurons were identified by green calcein fluorescence and dead neurons were identified by the red fluorescence of DNA-bound ethidium. Cells were examined and counted on a Nikon ${ }^{\circledR}$ Eclipse Ti-Eat at $20 \mathrm{x}$ 
magnification. At least three random fields were imaged per culture well (three replicate wells were used per experimental condition in each experiment) and about 500 cells were counted in each well. Six independent experiments were performed with different neuronal cultures. Cell viability was expressed as percentage relative to the untreated control cultures, which exhibited $85 \%$ cell viability on average.

\subsection{Determination of Mitochondrial Hydrogen Peroxide Gen-} eration. Cultures grown in $25 \mathrm{~mm}$ glass plates were transiently transfected with the HyperMito plasmid at 11-14 DIV, using a proportion of 1:2 DNA:Lipofectamine $2000^{\circledR}$. HyperMito is a fusion protein of the permuted circular yellow fluorescent protein (YFP) and the regulatory domain of the transcription factor OxyR, which contains two cysteines that oxidize in response to $\mathrm{H}_{2} \mathrm{O}_{2}$ generation and form a disulfide bridge producing a conformational change that causes an increase in YFP fluorescence [30]. One-day after transfection, cultures incubated in Neurobasal medium supplemented with B-27 were treated for $1.5 \mathrm{~h}$ with $0.1 \mu \mathrm{M}$ ATX, rinsed three times with modified Tyrode solution plus $0.1 \mu \mathrm{M}$ ATX, and maintained in this solution during the experiment. At the microscope stage, cultures were stimulated with $500 \mathrm{nM}$ $\mathrm{A} \beta \mathrm{O}$ s and fluorescence signals from neuronal cells (identified as such by morphology) were recorded every $6 \mathrm{~s}$ in a Carl Zeiss LSM Pascal 5 confocal microscope system using $63 \mathrm{x}$ Oil DIC objective, excitation $488 \mathrm{~nm}$, and argon laser beam. Changes in mitochondrial $\mathrm{H}_{2} \mathrm{O}_{2}$ levels are presented as $F / F_{0}$ values, where $F$ corresponds to the experimental fluorescence and $F_{0}$ corresponds to the basal fluorescence.

2.6. Nuclear Translocation of NFATc4-eGFP. Cultures grown in $25 \mathrm{~mm}$ glass plates were transiently transfected with a plasmid of a fusion protein encoding a green fluorescent protein (GFP) and NFATc4 [24] at 13-15 DIV using a proportion of 1:2 DNA: Lipofectamine $2000^{\circledR}$. Cultures maintained in Neurobasal medium (supplemented with B-27) were treated one day after transfection for $1.5 \mathrm{~h}$ with $0.1 \mu \mathrm{M}$ ATX, previous to the addition of $500 \mathrm{nM} \mathrm{A} \beta \mathrm{O}$ s for $6 \mathrm{~h}$. Neurons were then fixed with $4 \%$ paraformaldehyde, washed three times with PBS, and incubated with Hoechst for 5 minutes for nuclear staining. Covers were mounted in DAKO mounting medium for microscope observation. The subcellular localization of NFATc4-eGFP was visualized in cells using a Carl Zeiss LSM Pascal 5 laser scanning confocal with the 40x objective lens. Data were analyzed using the ImageJ software (NIH). To calculate the NFATc4 ratio of nucleus versus cytoplasm, the fluorescence intensity of nuclear NFATc4 was divided by the intensity of cytoplasmic NFATc4. Nuclear translocation of NFATc4 was determined by EGFP fluorescence intensity values from a region of interest (ROI) in the nucleus, as indicated by the overlap of EFGP staining with Hoechst nuclear staining. Background fluorescence was corrected by using a ROI devoid of cells and values were normalized to their respective areas.

2.7. RNA Isolation and PCR Analysis. To determine RyR2 mRNA levels, neurons were treated for $1.5 \mathrm{~h}$ with $0.1 \mu \mathrm{M}$ ATX prior to incubation with $500 \mathrm{nM} \mathrm{A} \beta$ Os for $6 \mathrm{~h}$. To extract RNA cells were lysed as described in previous work [25]. Total RNA was isolated using TRIzol reagent. To remove any contaminating genomic DNA, a DNAase digestion step with Ambion DNA-free ${ }^{\mathrm{TM}}$ Kit was included. RNA purity was assessed by the 260/280 absorbance ratio and RNA integrity by gel electrophoresis. cDNA was synthesized from total RNA $(2 \mu \mathrm{g})$ using the ImProm-II ${ }^{\mathrm{TM}}$ Reverse Transcriptase kit. Twenty-five ng of cDNA was used in $20 \mu \mathrm{L}$ final volume for PCR amplification (Applied Biosystem Thermal Cycler). Amplification was performed using the primers and conditions detailed previously [25]. Real-time quantitative PCR (qPCR) was performed in an amplification system (MX3000P) using the DNA binding dye SYBR green (Brilliant III SYBER-GREEN Master Mix). Levels of RyR mRNA were calculated by the relative $2^{-\Delta \Delta \mathrm{Ct}}$ method [31] and normalized with respect to levels of $\beta$-actin mRNA. Dissociation curves were analyzed to verify purity of products. All samples were run in triplicate.

2.8. Statistics. Results are expressed as mean \pm SEM. The significance of differences was evaluated using Student's $t$ test for paired data and with one-way ANOVA followed by Bonferroni's post hoc test for multiple determinations.

\section{Results}

Previous studies showed that ATX, by attenuating oxidative damage, lipid peroxidation, and inhibiting the mitochondrial-related apoptotic pathway, protects hippocampal neurons against epilepsy-induced cellular loss [32]. Additionally, ATX prevents inflammation injury and improves cognition in diabetic mice [33]. To investigate the possible neuroprotective role of ATX against the toxic effects produced by $\mathrm{A} \beta \mathrm{O}$, we treated primary hippocampal cultures with sublethal concentrations of $\mathrm{A} \beta \mathrm{Os}(500 \mathrm{nM})$ in the presence or absence of ATX.

We first determined cell viability of primary hippocampal cultures (14 DIV) exposed for $24 \mathrm{~h}$ to different concentrations of ATX (ranging from 0.001 to $100 \mu \mathrm{M}$ ). Figures $1(\mathrm{a})-1(\mathrm{~h})$ show representative live/dead images of control cultures (a), of cultures treated with different ATX concentrations ((b)(g)) or with $250 \mu \mathrm{M} \mathrm{H}_{2} \mathrm{O}_{2}$ (h) to induce cell death. Live cells display calcein green fluorescence while dead cells exhibit punctuated ethidium red fluorescence. Figure 1(i) shows the quantitative analysis of cell viability expressed as percentages of control, determined in six independent experiments performed in six neuronal cultures. Control neurons presented at least $85 \%$ cell survival. Treatment with ATX concentrations $\leq 10 \mu \mathrm{M}$ did not decrease cell viability when compared to control cultures, while treatment with $100 \mu \mathrm{M}$ ATX induced $20 \%$ cell death. For comparison, treatment with $250 \mu \mathrm{M}$ $\mathrm{H}_{2} \mathrm{O}_{2}$ elicited $40 \%$ neuronal death.

Considerable evidence points to brain oxidative stress as an important event in the early stages of $\mathrm{AD}$ [5]. In particular, enhanced generation of ROS, such as $\mathrm{H}_{2} \mathrm{O}_{2}$ and hydroxyl radicals, has been proposed as a key molecular mechanism underlying the pathogenesis of AD [34]. Since 


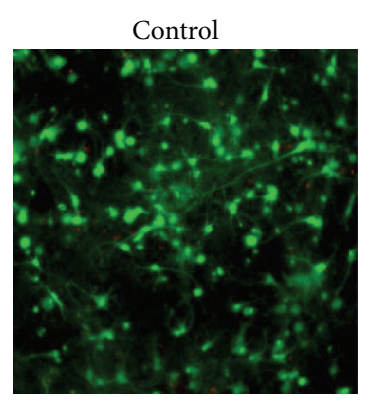

(a)

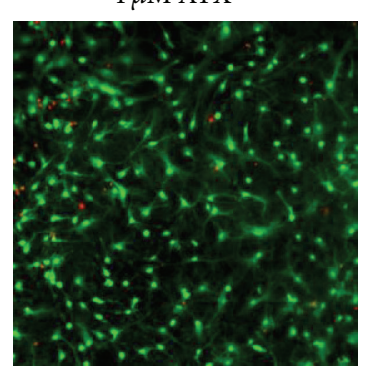

(e)

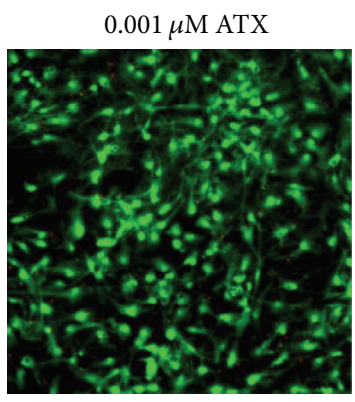

(b)

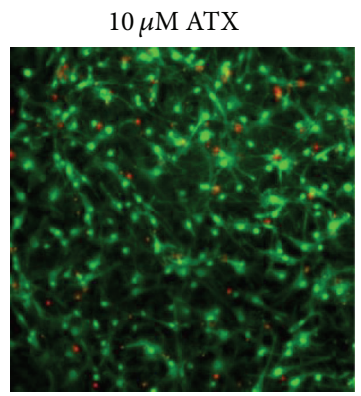

(f)

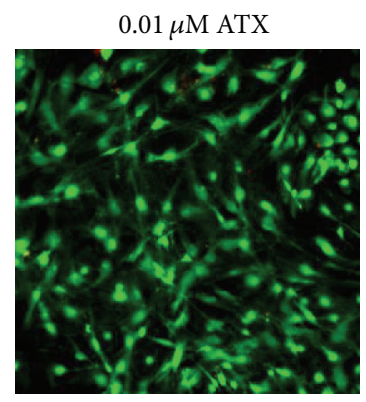

(c)

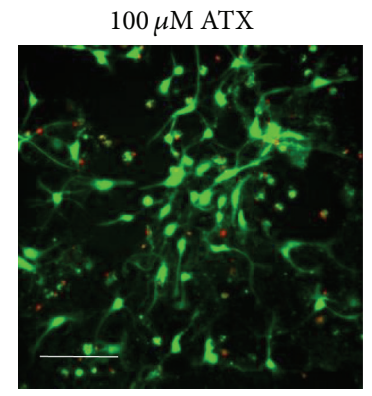

(g)

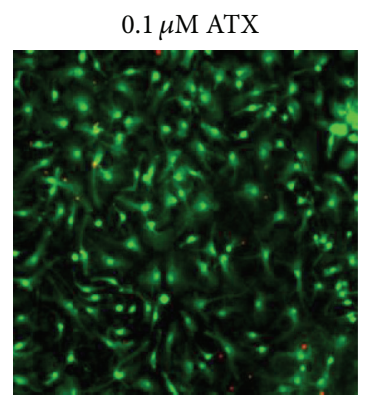

(d)

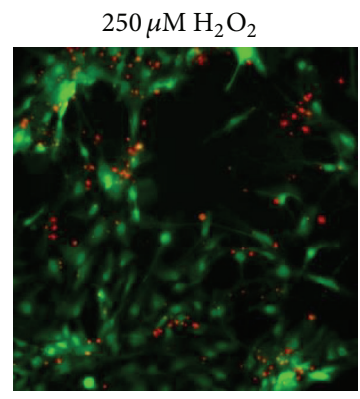

(h)

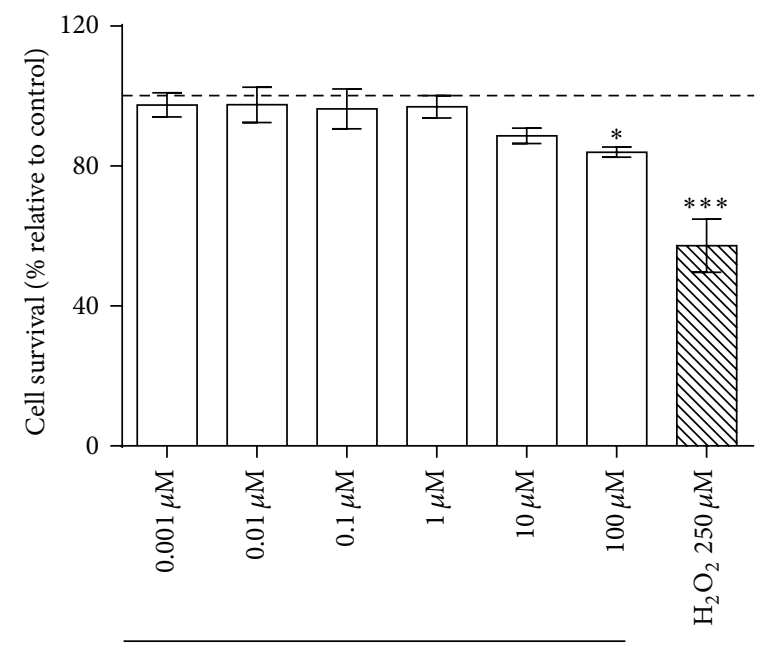

Astaxanthin

(i)

FIGURE 1: Lack of toxicity of ATX $(\leq 10 \mu \mathrm{M})$ to primary hippocampal cultures. Representative live/dead fluorescence images $((\mathrm{a})-(\mathrm{h}))$ of neuronal hippocampal cultures (13-15 DIV) incubated for $24 \mathrm{~h}$ in the presence of vehicle (a) or treated with $0.001 \mu \mathrm{M}(\mathrm{b}), 0.01 \mu \mathrm{M}(\mathrm{c})$, $0.1 \mu \mathrm{M}(\mathrm{d}), 1 \mu \mathrm{M}(\mathrm{e}), 10 \mu \mathrm{M}$ (f), and $100 \mu \mathrm{M}$ (g) ATX. In (h), $250 \mu \mathrm{M} \mathrm{H}_{2} \mathrm{O}_{2}$ was used to induce cell death. Live and dead neurons were identified by green calcein and red DNA-bound ethidium fluorescence, respectively. Scale bar: $50 \mu \mathrm{m}$. (i) shows quantitative analysis of cell survival incubated with different concentrations of ATX (white bars) and under $\mathrm{H}_{2} \mathrm{O}_{2}$ stimulation (hatched bar). Results are expressed as percentages relative to the viability of the control, untreated cultures. Values correspond to mean \pm SE of six independent experiments $(n=6$, corresponding to cultures from 6 different animals; in all experiments, each condition was tested at least in triplicate), with different neuronal cultures. Control cultures exhibited $85 \%$ of cell viability on average. Statistically significant differences among experimental conditions were evaluated by one-way ANOVA followed by Bonferroni's multiple comparison test $\left({ }^{*} p<0.05\right.$ and ${ }^{* * *} p<0.0001$ compared to control).

A $\beta$ Os induce neuronal ROS production [9], including mitochondrial ROS production [35], we tested whether ATX prevents mitochondrial $\mathrm{H}_{2} \mathrm{O}_{2}$ generation induced by $\mathrm{A} \beta \mathrm{Os}$. To this purpose, we transfected neurons with a plasmid that codes for the HyperMito protein, a $\mathrm{H}_{2} \mathrm{O}_{2}$ fluorescent sensor with mitochondrial destination; $24 \mathrm{~h}$ after transfection we added $\mathrm{A} \beta \mathrm{Os}(500 \mathrm{nM})$ to the cultures and recorded fluorescence levels for 20 minutes. The representative images illustrated in Figure 2 show that control neurons (Figure 2(a)) did not display significant fluorescence changes when comparing the image taken before vehicle addition (250 s), with the final image collected at the end of the record (1250 s). 


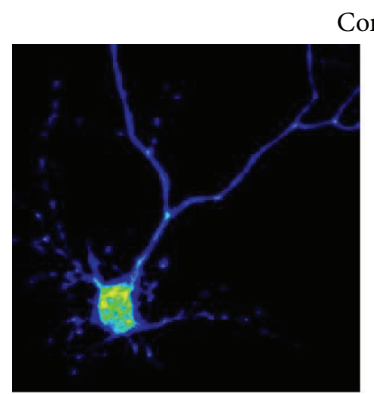

Before
Control

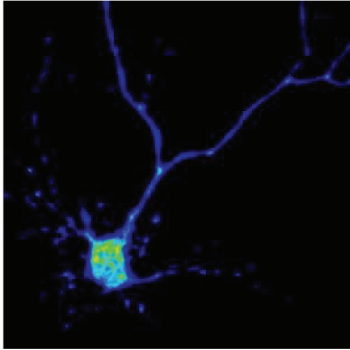

After

(a)

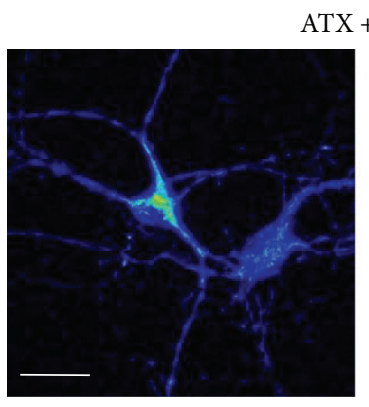

Before

(c)

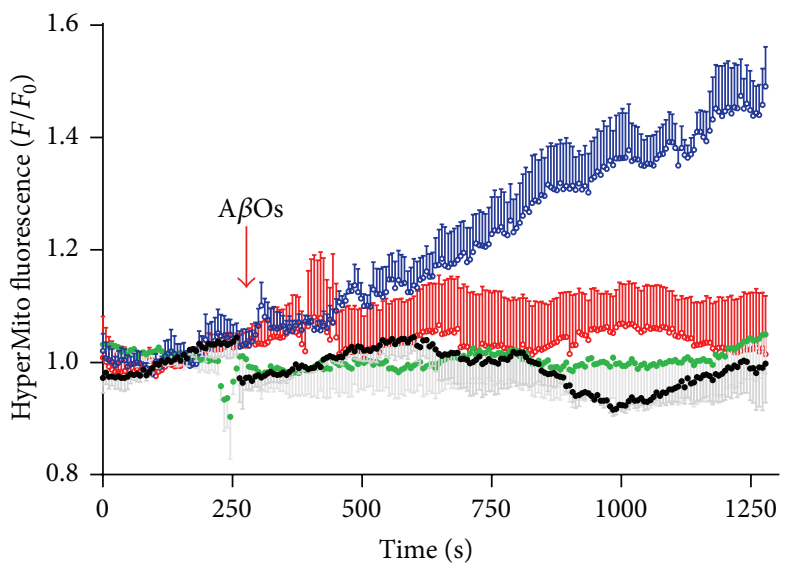

- Control

- $\mathrm{A} \beta O \mathrm{~s}$
- $\mathrm{ATX}+\mathrm{A} \beta \mathrm{Os}$

- ATX

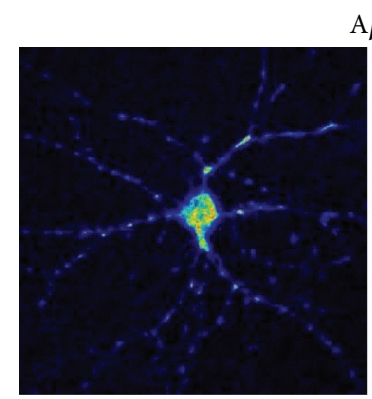

Before

$\mathrm{A} \beta \mathrm{Os}$

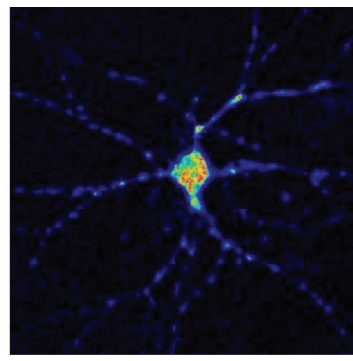

After

(b)

ATX

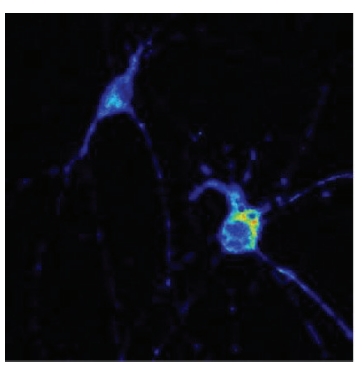

Before

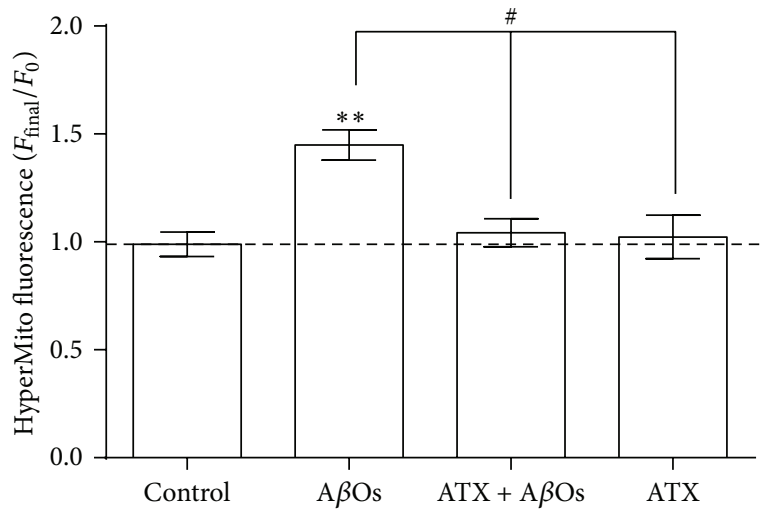

(e)

(f)

FIgURE 2: ATX prevents mitochondrial $\mathrm{H}_{2} \mathrm{O}_{2}$ generation induced by $\mathrm{A} \beta \mathrm{O}$. Hippocampal neurons (13-15 DIV) were transfected with HyperMito, $24 \mathrm{~h}$ before the experimental maneuvers. ((a)-(d)) show representative pseudocolor images of hippocampal neurons expressing the HyperMito protein, collected before $(250 \mathrm{~s}$, left images) or $1000 \mathrm{~s}$ after (1250 s, right images) the addition of vehicle ((a) and (d)) or of $500 \mathrm{nM} \mathrm{A} \beta \mathrm{Os}((\mathrm{b})$ and (c)). Higher fluorescence intensity levels are expressed by the red color in a pseudocolor scale, while lower intensity levels are expressed by blue color. Scale bar: $10 \mu \mathrm{m}$. (e) shows representative time courses of HyperMito fluorescence, recorded in neuronal soma after the addition of vehicle (black symbols) or $500 \mathrm{nM} \mathrm{A} \beta \mathrm{Os}$ in the absence (blue symbols) or presence (green symbols) of $0.1 \mu \mathrm{M}$ ATX preincubated for $1.5 \mathrm{~h}$, which alone did not induce changes in HyperMito fluorescence (red symbols). Fluorescence changes (mean \pm $\mathrm{SE})$ are expressed as $\left(F / F_{0}\right)$, where $F_{0}$ corresponds to the basal fluorescence recorded in the soma before $\mathrm{A} \beta \mathrm{Os}$ addition. The graph illustrates average values from 2 ROIs registered at the soma of neurons recorded in the visual field $(n=4)$. Values correspond to four different experiments performed in four cultures from four different animals; each condition was tested in duplicate. (f) shows the values of $F / F_{0}$ obtained at the end of the experiment (time $1250 \mathrm{~s}$ ) to each condition and bars represent mean \pm SE. Statistically significant differences among experimental conditions were evaluated by one-way ANOVA followed by Bonferroni's multiple comparison test $\left({ }^{* *} p<0.001\right.$ compared to control; ${ }^{\#} p<0.05$ compared to indicated conditions). 
Hippocampal neurons responded to $A \beta O$ s with a significant increase in probe fluorescence, as illustrated by the representative images (Figure 2(b)), recorded before (250 s) and $1000 \mathrm{~s}$ after $\mathrm{A} \beta \mathrm{Os}$ addition (1250 s). In contrast, neurons preincubated for $1.5 \mathrm{~h}$ with $0.1 \mu \mathrm{M}$ ATX and then treated with $500 \mathrm{nM} \mathrm{A} \beta$ Os (Figure 1(c)) or preincubated with ATX and vehicle (Figure 1(d)) did not exhibit significant fluorescence changes when comparing the images taken at the final and the initial time point, recorded before vehicle or $\mathrm{A} \beta \mathrm{Os}$ addition. The time courses of average fluorescence changes recorded in neurons stimulated with $500 \mathrm{nM} \mathrm{A} \beta$ Os or vehicle in the presence or absence of ATX, shown in Figure 2(e), indicate that $\mathrm{A} \beta \mathrm{O}$ s addition to control neurons promoted mitochondrial $\mathrm{H}_{2} \mathrm{O}_{2}$ production within minutes (blue trace). Neurons preincubated for $1.5 \mathrm{~h}$ with ATX $(0.1 \mu \mathrm{M})$ did not exhibit changes in fluorescence following addition of $500 \mathrm{nM}$ $\mathrm{A} \beta \mathrm{Os}$ (green trace) or of saline (red trace). The relative fluorescence $\left(F_{\text {final }} / F_{0}\right)$ values of neurons maintained in different conditions, plotted in Figure 2(f), show that $500 \mathrm{nM}$ A $\beta$ Os induced a significant increase in mitochondrial $\mathrm{H}_{2} \mathrm{O}_{2}$ content, which was prevented by preincubation with $0.1 \mu \mathrm{M}$ ATX.

A requisite step for the sustained synaptic plasticity processes underlying learning and memory is an elevation in intracellular-free $\mathrm{Ca}^{2+}$ concentration, which plays a central role in $\mathrm{Ca}^{2+}$-dependent gene transcription [36-38]. Indeed, defective $\mathrm{Ca}^{2+}$ signaling is believed to underlie $\mathrm{AD}$ neuronal pathology [39]. The activation of calcineurin, which promotes the downstream stimulation of the transcriptional factor NFAT that is engaged in dendritic and axonal development, synaptogenesis, and neuronal survival [40], plays a prominent role among activity-dependent $\mathrm{Ca}^{2+}$-signaling pathways. In particular, the isoform NFATc4 is activated by prolonged $\mathrm{Ca}^{2+}$ signals [41]. Moreover, activation of NFATc4 has been demonstrated in vitro and in vivo in $\mathrm{AD}$ [42]. Of importance, NFATc 4 activation by A $\beta$ invokes morphological changes such as neuritic dystrophy and loss of dendritic branching and spines, effects that are prevented and reverted by inhibitors of the calcineurin/NFAT pathway [42, 43]. Also postmortem studies showed that, in the hippocampus of patients, activation of NFATc4 correlates with cognitive deficits $[44,45]$. To investigate whether preincubation with ATX prevents the activation of NFATc4 by A $\beta$ Os, we determined its translocation to the nucleus in hippocampal neurons transfected with plasmid codifying for the fusion protein of NFATc4 with GFP. We preincubated neurons $24 \mathrm{~h}$ after transfection with $0.1 \mu \mathrm{M}$ ATX for $1.5 \mathrm{~h}$ and exposed them to $\mathrm{A} \beta \mathrm{O}$ s $(500 \mathrm{nM})$ for an additional $6 \mathrm{~h}$ period. As illustrated in Figure 3(a), control neurons displayed GFP fluorescence mainly in the cytoplasm, indicating that in this condition NFATc4 was inactive. Incubation with $A \beta O$ s for $6 \mathrm{~h}$ induced nuclear translocation of NFATc4/GFP, indicating that $\mathrm{A} \beta \mathrm{O}$ s induce NFATc4 activation (Figure 3(b)). Previous incubation with ATX did not change the cytoplasmic distribution of NFATc4 in neurons incubated with $A \beta O$ s for $6 \mathrm{~h}$ (Figure 3(c)) or in control neurons (Figure 3(d)). The average results from four experiments (Figure 3(e)) show that incubation of neurons with $\mathrm{A} \beta \mathrm{O}$ s for $6 \mathrm{~h}$ increased 3 -fold the nuclear/cytoplasmic ratio; this increase did not occur in neurons pretreated with ATX.

We have previously shown that brain derived neurotrophic factor (BDNF) positively regulates the expression of intracellular RyR2 $\mathrm{Ca}^{2+}$ channels in hippocampal cultures [46], whereas $\mathrm{A} \beta \mathrm{Os}$ downregulate RyR2 expression during synaptotoxicity [25]. In agreement with our previous results, incubation for $6 \mathrm{~h}$ with $\mathrm{A} \beta \mathrm{Os}(500 \mathrm{nM})$ significantly decreased RyR2 mRNA levels to approximately $54 \%$ (Figure 4(a)). Preincubation with ATX $(0.10 \mu \mathrm{M})$ did not modify RyR2 mRNA levels but resulted in complete prevention of the reduction of RyR 2 mRNA levels promoted by $\mathrm{A} \beta \mathrm{O}$ s (Figure $4(\mathrm{a})$ ). These results suggest a possible link between mitochondrial ROS generation and RyR2 expression. In addition, we found that the general antioxidant agent N-acetyl-L-cysteine (NAC), which is a cellular precursor of glutathione, also protects primary hippocampal neurons from the RyR2 mRNA decrease induced by $\mathrm{A} \beta \mathrm{Os}$ (Figure 4(b)). Although the results presented in Figure 4 may be interpreted as an indication that RyR2 protein content was better preserved by treatment with ATX compared to NAC, these effects were not significantly different (not shown).

\section{Discussion}

Alzheimer's disease is the most common form of dementia worldwide. Among the most important risk factors for the development of $\mathrm{AD}$ are human conditions that have been associated with oxidative stress and chronic inflammation, which include aging, cardiovascular diseases, diabetes, hypertension, brain trauma, and high alcohol consumption $[47,48]$. On the other hand, there are factors considered protective, as regular exercise and the consumption of diets rich in antioxidants $[48,49]$. In the search for therapeutic strategies that could prevent $\mathrm{AD}$, several attempts have been made to slow the disease progression with antioxidant agents [50]. Briefly, several studies carried out in in vitro and in vivo models of $\mathrm{AD}$ have shown some positive results of antioxidants. The main mechanisms proposed to explain these effects are (1) mimicking endogenous catalytic enzymes (mainly superoxide dismutases (SOD), catalases (CAT)) [51] and metabolic precursors of endogenous antioxidants system (Glutathione) [52]; (2) acting like ROS scavenger; and (3) causing SIRT activation [53]. Although antioxidants have been widely studied as an alternative strategy to prevent or treat $\mathrm{AD}$, direct evidence is still required to support their use in the treatment of patients suffering from $\mathrm{AD}[54,55]$.

Antioxidant agents are distinct chemical entities with structures that command their different modes of action; this structural diversity imparts each antioxidant agent with a unique biochemical profile, which is reflected in different sites of action and biological activities. ATX is classified as a lipophilic antioxidant of the carotenoid family, and its main protective mechanisms rely on its capacity to act as a singlet oxygen quencher and free radical scavenger. However, after scavenging reactive-free radicals, ATX is transformed into a carotenyl radical by hydrogen abstraction; this process can lead to a switch from a beneficial antioxidant agent 


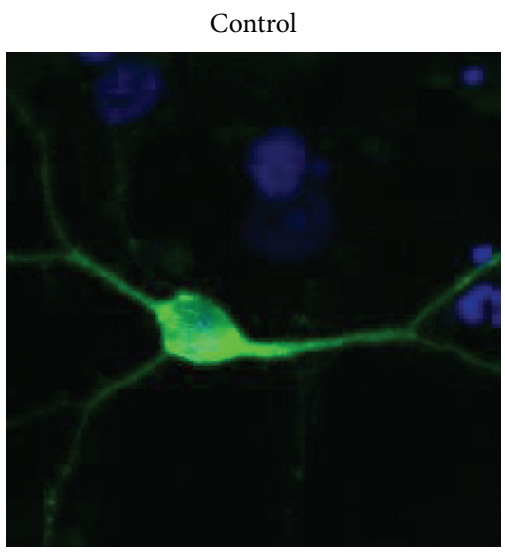

(a)

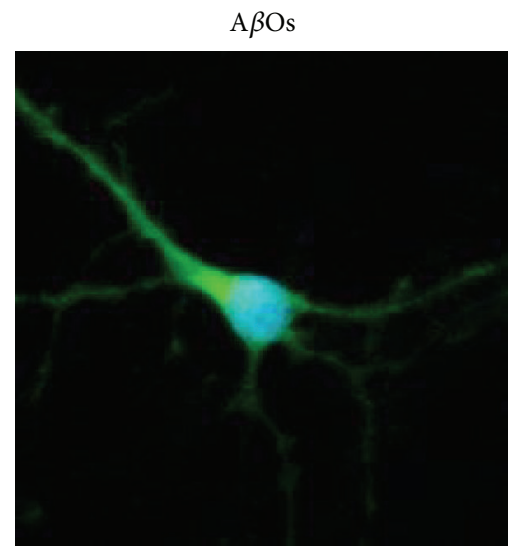

(b)

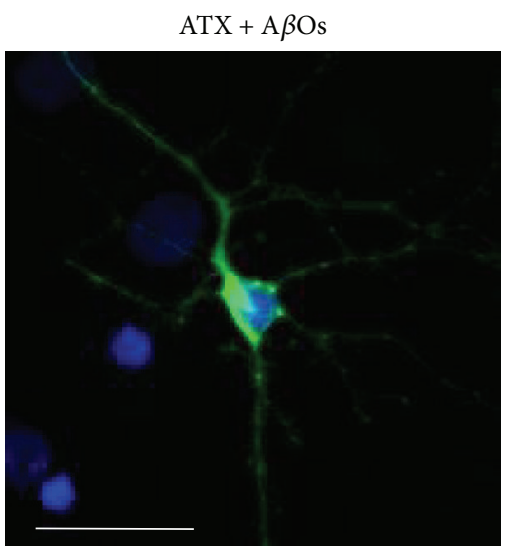

(c)

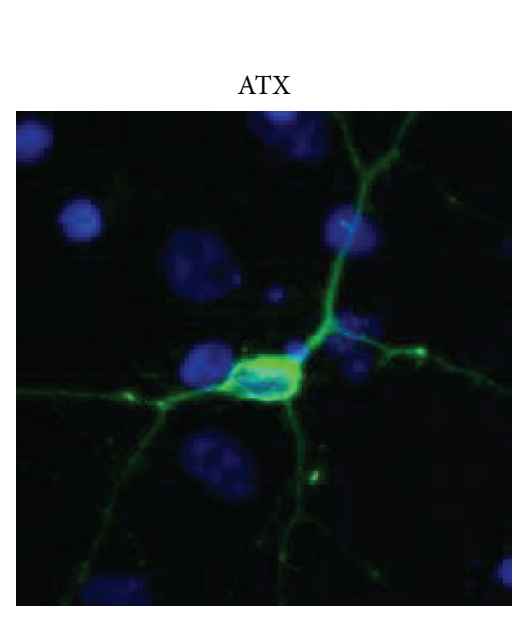

(d)

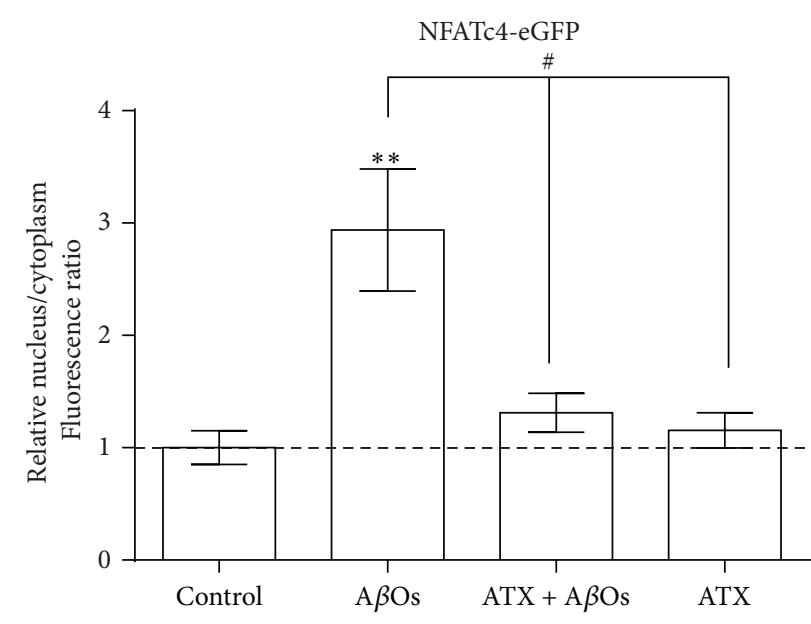

(e)

FIGURE 3: ATX prevents A $\beta$ Os-induced NFATc4 activation. Hippocampal neurons (13-15 DIV) were transfected with EGFP-NFATc4 $24 \mathrm{~h}$ before the experiments. ((a)-(d)) show representative images of intracellular distribution of EGFP-NFATc4 (green fluorescence) and of nuclear staining with Hoechst (blue fluorescence) in hippocampal neurons. (a) Neurons treated with vehicle, (b) stimulated with 500 nM $\mathrm{A} \beta \mathrm{Os}$ for $6 \mathrm{~h}$, (c) preincubated with $0.1 \mu \mathrm{M}$ ATX for $1.5 \mathrm{~h}$ before A $\beta$ Os addition, or (d) incubated with ATX for $7.5 \mathrm{~h}$. Scale bar: $10 \mu \mathrm{m}$. (e) shows the quantification of four different experiments $(n=4)$ in cultures from four different animals; each condition was tested in duplicate (in total, 15-25 cells were analyzed per condition). The results are expressed as the mean ratio of nuclear/cytoplasmic fluorescence intensity \pm $\mathrm{SE}$, relative to control cells. Statistically significant differences among experimental conditions were evaluated by one-way ANOVA followed by Bonferroni's multiple comparison test $\left({ }^{* *} p<0.001\right.$ compared to control; ${ }^{*} p<0.05$ compared to indicated conditions).

to a damaging prooxidative one, which could explain ATX toxicity when used at higher concentrations $(100 \mu \mathrm{M})[56]$. Here, we studied the protective properties of ATX against the noxious effects of $\mathrm{A} \beta \mathrm{O}$ s on primary hippocampal cultures and compared some of its effects with the protective actions of NAC. We also compared the effects of NAC because this is a classical and very widely studied antioxidant. Although NAC also acts as a ROS scavenger, its principal action stems from its role as a precursor of cysteine, the rate-limiting factor in the de novo synthesis of glutathione (GSH). In this sense, contrary to ATX, NAC is an indirect antioxidant, which, as a precursor of the antioxidant GSH, has a safer toxicity profile, allowing the use of higher concentrations [57]. Both antioxidant agents have been studied in the context of central nervous system disorders $[16,58]$, but evidence related to NAC is more abundant.
We have previously shown that incubation of hippocampal neurons in vitro with NAC, a glutathione precursor molecule with antioxidant properties, completely prevents the aberrant increase in intracellular $\mathrm{Ca}^{2+}$ levels and the mitochondrial fragmentation induced $\mathrm{A} \beta \mathrm{Os}[25,52]$. In previous work from our laboratory, we have also shown that reducing agents suppress $\mathrm{RyR}$ activation by $\mathrm{Ca}^{2+}$ in cortical neurons [59]. Also the administration of NAC through drinking water to a transgenic mouse model of $\mathrm{AD}$ (mouse APP/PS-1) suppressed the protein oxidation and nitrosylation in the brains of mice aged 9 and 12 months [60]. The above results are consistent with the idea that NAC modulates the activity of RyR by avoiding the aberrant intracellular ROS increase and hence the enhanced $\mathrm{Ca}^{2+}$ release produced by ROS-modified $\mathrm{RyR}$, induced by $\mathrm{A} \beta \mathrm{Os}$. 


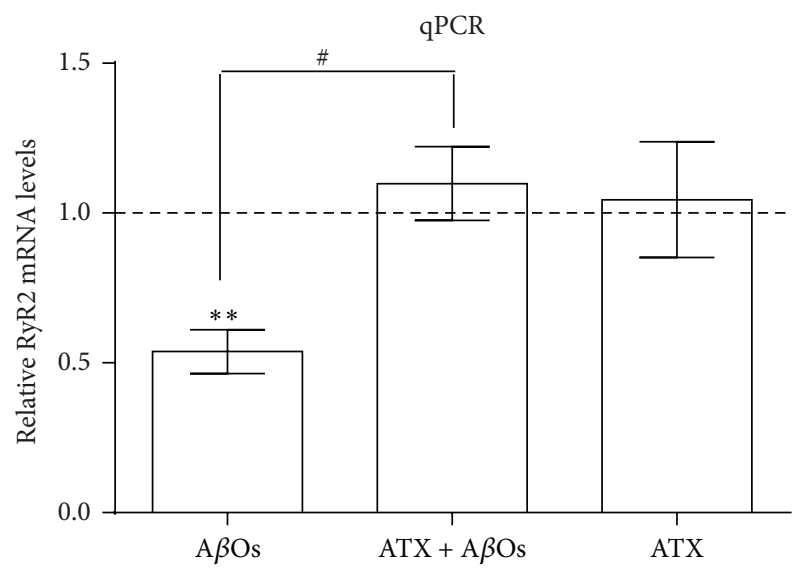

(a)

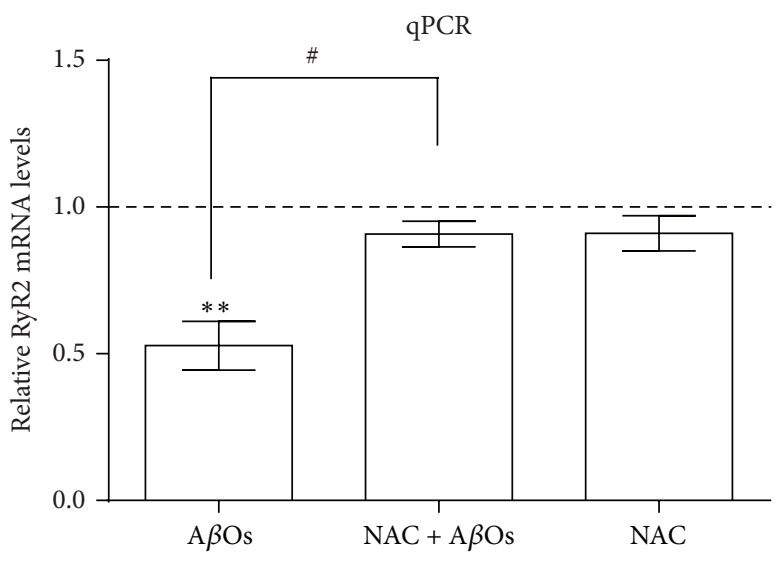

(b)

Figure 4: ATX prevents A $\beta$ Os-induced RyR2 mRNA downregulation. Hippocampal cultures were preincubated with $0.1 \mu \mathrm{M}$ ATX (a) or $10 \mathrm{mM}$ of NAC (b) for $1.5 \mathrm{~h}$ or 30 minutes, respectively, before incubation for $6 \mathrm{~h}$ with $500 \mathrm{nM}$ A $\beta$ Os. Relative RyR2 mRNA levels were determined with qPCR, normalized to $\beta$-actin mRNA levels, and expressed as fold over control. Values represent mean \pm SE $(n=6)$ from experiments performed in cultures from six different animals; each condition was tested in triplicate. Statistically significant differences among experimental conditions were evaluated by one-way ANOVA followed by Bonferroni's multiple comparison test $\left({ }^{* *} p<0.001\right.$ compared to control; ${ }^{\#} p<0.05$ compared to indicated conditions).

Astaxanthin is a natural carotenoid product that is used in nutritional supplements, which can be extracted from Lithodes antarcticus. ATX has been shown to quench singlet oxygen and to scavenge free radicals [61]; ATX antioxidant properties reside in its polar ionic rings and nonpolar conjugated carbon-carbon bonds and are 10 -fold greater than those of other carotenoids [62]. In addition to the ROS scavenging properties attributed to ATX, several studies have shown that ATX, alone or in combination with omega-3 fatty acids, protects cells by inducing antioxidant activity via the nuclear factor (erythroid-derived 2)-like 2 (Nrf2) Nrf2/heme oxygenase-1 (HO-1) signaling pathway [63-65]. Several studies have implicated Nrf2 in the induction of HO-1, which is the enzyme that catalyzes the first and rate-limiting step of heme metabolism [66, 67]. HO-1 activity protects tissue during inflammatory stress in various conditions through the degradation of prooxidant heme and the production of carbon monoxide (CO) and bilirubin, both of which have anti-inflammatory and antiapoptotic properties, especially in ROS-dependent perturbations associated with metabolic syndrome [67].

In this work, we tested the possible neuroprotective effects of ATX on some of the noxious effects induced by $\mathrm{A} \beta \mathrm{O}$ s on primary hippocampal cultures. We found that ATX prevented the mitochondrial generation of $\mathrm{H}_{2} \mathrm{O}_{2}$, the nuclear translocation of NFATC4, and the decrease of RyR2 mRNA levels induced by $A \beta O s$. These protective effects may result from the reduction of intracellular ROS promoted by ATX. Although ROS have important roles in cell signaling and normal neuronal function, excessive ROS generation, such as that produced by $\mathrm{A} \beta \mathrm{Os}$, has deleterious effects on neuronal function, which include the significant damage to DNA, RNA, proteins, and polyunsaturated fatty acids in lipids caused by irreversible oxidation. Normally, cells defend themselves against ROS damage through intracellular and extracellular defenses, in particular through enzymes such as SOD, CAT, lactoperoxidases, and glutathione peroxidases. ATX supplementation not only lowers ROS levels but also leads to an important functional recovery of the antioxidant network [68], including SOD, which catalyzes the dismutation of superoxide anion to $\mathrm{O}_{2}$ and $\mathrm{H}_{2} \mathrm{O}_{2}$, and CAT, which protects cells from oxidative damage by catalyzing the decomposition of $\mathrm{H}_{2} \mathrm{O}_{2}$ to water and $\mathrm{O}_{2}$.

Recent clinical studies showed that ATX promotes significant reductions in cardiovascular risk markers of oxidative stress and inflammation [69]; ATX also has considerable potential for both the prevention and treatment of various chronic inflammatory disorders, such as cancer, asthma, rheumatoid arthritis, metabolic syndrome, diabetes, and diabetic nephropathy, as well as gastrointestinal, hepatic, and neurodegenerative diseases [56]. In rats, ATX supplementation in the diet for four weeks markedly decreases the level of malondialdehyde (MDA), nitric oxide, and advanced protein oxidation products in the cortex, striatum, hypothalamus, hippocampus, and cerebellum [68]. Also ATX increases the activity of CAT and SOD enzymes as well as the level of glutathione in the brain [68]. Additionally, ATX exhibits protective effects against the neurotoxicity induced by Abeta $25-35$ peptide aggregates in PC12 and neuroblastoma (SH-SY5Y) cells $[70,71]$. These results are in agreement with the main conclusions presented in this work.

Besides the role of ROS and oxidative stress in $\mathrm{AD}$, there are many studies linking this disease with a sustained increase in intracellular $\mathrm{Ca}^{2+}$ levels $[39,72,73]$. We have previously reported that $\mathrm{A} \beta \mathrm{O}$ s addition to primary hippocampal neurons causes an increase in $\mathrm{Ca}^{2+}$ entry to the cytoplasm via NMDA receptors, which promotes RyRmediated $\mathrm{Ca}^{2+}$ release [25]. We also showed that previous 


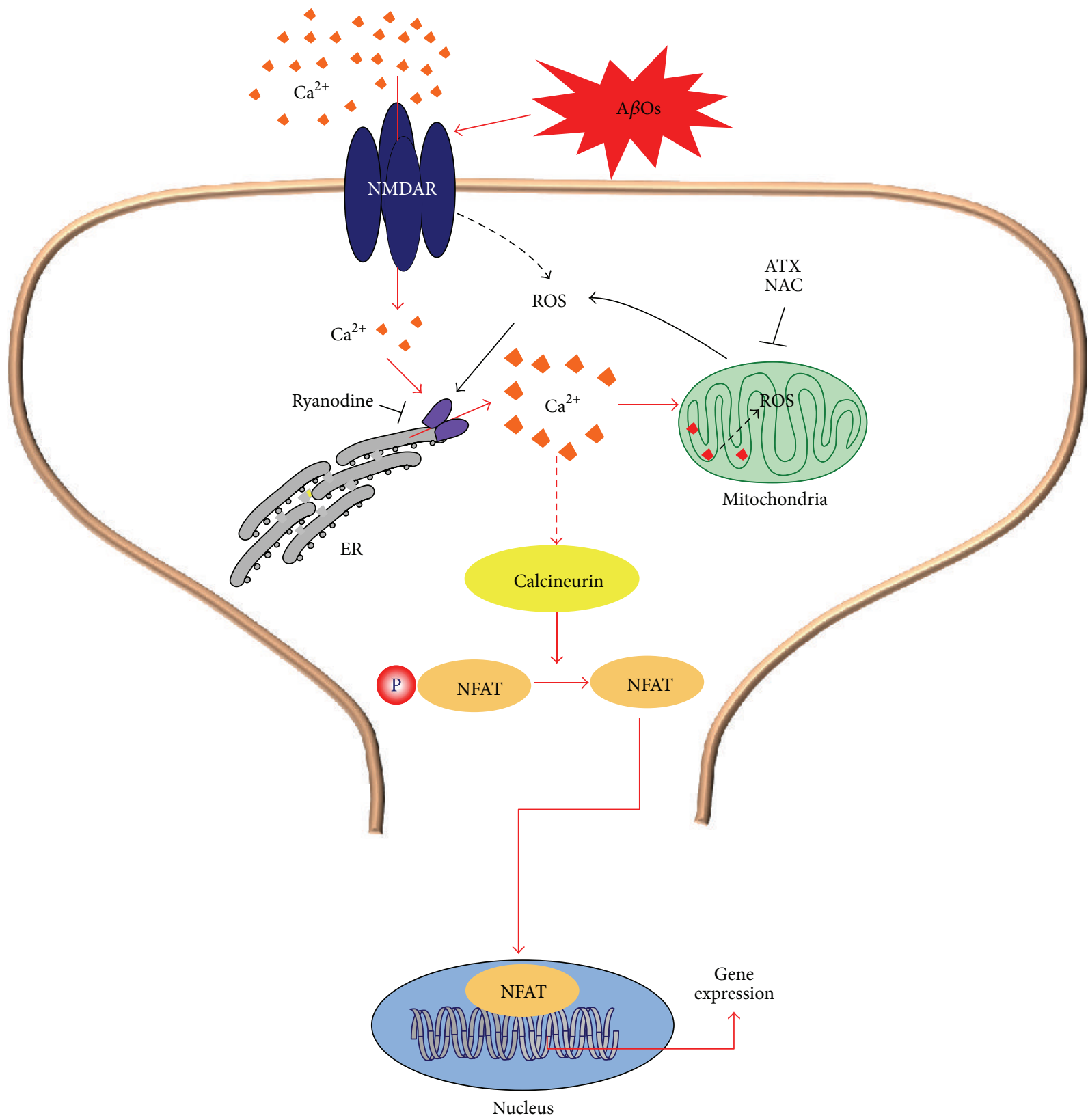

8 RyR

$\mathrm{Ca}^{2+}$

FIGURE 5: Scheme showing a possible mechanism to explain ATX neuroprotection over the deleterious effects of $\mathrm{A} \beta \mathrm{O}$. $\mathrm{A} \beta \mathrm{O}$ s promote increased ROS generation and induce abnormal $\mathrm{Ca}^{2+}$ signals in primary hippocampal neurons, which arise initially from $\mathrm{Ca}^{2+}$ entry through NMDA receptors; these entry signals are subsequently amplified by $\mathrm{Ca}^{2+}$ release through RyR channels costimulated by $\mathrm{Ca}^{2+}$ and the increased ROS levels generated response to A $\beta$ Os [25]. Activation of RyR-mediated $\mathrm{Ca}^{2+}$ release by ROS [59, 77] induces mitochondrial Ca ${ }^{2+}$-uptake, which is prevented by ryanodine at inhibitory concentrations [27]. These abnormal cytoplasmic $\mathrm{Ca}^{+2}$ signals promote NFATc4 translocation, which induces deleterious changes in gene expression and dendritic spine morphology [42]. ATX and NAC, either by scavenging ROS/RNS or by increasing antioxidant defenses, would prevent abnormal $\mathrm{A} \beta \mathrm{O}$ s induced RyR-mediated $\mathrm{Ca}^{2+}$-induced $\mathrm{Ca}^{2+}$ release and thus would prevent the harmful effects of enhanced NFAT nuclear translocation. 
incubation of primary neurons with NAC prevents the emergence of sustained $\mathrm{Ca}^{2+}$ signals induced by $\mathrm{A} \beta \mathrm{O}$ s [52]. These findings emphasize the participation of ROS in the maintenance of the $\mathrm{Ca}^{2+}$ signals induced by $\mathrm{A} \beta \mathrm{O}$. On the other hand, intracellular $\mathrm{Ca}^{2+}$ chelators such as BAPTA-AM prevent the ROS generation induced by $\mathrm{A} \beta \mathrm{O}$, indicating that there is a crosstalk between the ROS and $\mathrm{Ca}^{2+}$ signals induced by $\mathrm{A} \beta \mathrm{Os}$ [9]. In this context, the RyR channel appears as an important actor since its activity and expression are regulated by this crosstalk [74]; thus, RyR channels act as coincident detectors of $\mathrm{Ca}^{2+}$ and ROS due to the presence of cysteine residues that are reversible modified by oxidants, enhancing RyR activation by $\mathrm{Ca}^{2+}$ [75]. We showed that incubation of primary hippocampal neurons with $\mathrm{A} \beta \mathrm{O}$ s causes an important downregulation of RyR2 mRNA and protein contents and proposed that these reductions are crucial to the synaptotoxicity induced by $\mathrm{A} \beta \mathrm{O}$ [ [25]. Of note, postmortem samples of patients who died with $\mathrm{AD}$ display significantly reduced RyR2 expression at early stages of the disease [76].

Dysregulation of $\mathrm{Ca}^{2+}$-dependent gene transcription plays a critical role in synaptic plasticity and memory defects [77]. A $\beta O$ s induce calcineurin activation, which leads in turn to activation of its canonical target, the transcriptional factor NFAT. The damage observed in the cortex and hippocampus of postmortem $\mathrm{AD}$ patients during the progression of the disease, correlates with activation of the calcineurin/NFAT pathway in both glial and neuronal cells $[44,45]$. Activation of this pathway, even in the absence of $\mathrm{A} \beta$, is sufficient to produce a virtual phenocopy of $\mathrm{A} \beta$-induced dystrophic neurites, dendritic simplification, and dendritic spine loss in both neurons in culture and in adult mouse brain [42]. Thus, $\mathrm{A} \beta \mathrm{O}$ s appear to mediate the neurodegeneration of $\mathrm{AD}$, at least in part, through calcineurin activation and subsequent stimulation of NFAT-mediated downstream cascades.

Calcineurin is susceptible to significant (up to 15 times) and reversible activation by $\mathrm{Ca}^{2+} / \mathrm{CaM}$. This activation is favored during chronic elevations of $\mathrm{Ca}^{2+}$ in the cytoplasm resulting from ER stress caused by exposure to misfolded proteins [78]. However, calcineurin activity is also redoxsensitive, so that oxidation of calcineurin strongly inhibits its phosphatase activity. Some possible mechanisms to explain this apparent paradox, that is, increased activity in conditions of increased ROS generation, have been discussed in studies from other groups $[78,79]$. Cleaved forms of the enzyme, which were found in $\mathrm{AD}$ brains [79], are constitutively active.

Here, we demonstrated for the first time that ATX inhibits the nuclear translocation of NFAT induced by $\mathrm{A} \beta \mathrm{Os}$, suggesting that the calcineurin/NFAT pathway responds to the increased neuronal oxidative tonus induced by $\mathrm{A} \beta \mathrm{O}$. Additionally, we show that ATX inhibits the downregulation of RyR 2 mRNA levels promoted by A $\beta$ Os. These results suggest that excessive ROS decrease RyR2 expression, although it is not known if the calcineurin/NFAT pathway mediates this decrease. Previous work indicates that the RyR2 protein plays an important role in hippocampal synaptic plasticity processes [77], so its downregulation by $\mathrm{A} \beta \mathrm{O}$ s may also contribute to their synaptotoxic effects. We previously showed that incubation of primary hippocampal neurons with $\mathrm{A} \beta \mathrm{O}$ s for a period of $6 \mathrm{~h}$ prevents the rapid spine remodeling prompted by caffeine-induced RyR-mediated $\mathrm{Ca}^{2+}$ release or by BDNF, which also requires RyR-mediated $\mathrm{Ca}^{2+}$ signals; these results suggest that the RyR2 decrease induced by $\mathrm{A} \beta \mathrm{Os}$ produces a significant reduction of RyR2-mediated $\mathrm{Ca}^{2+}$ signals in response to BDNF, leading to defective synaptic remodeling [25]. Thus, decreased RyR2 protein expression may contribute to impair synaptic plasticity in AD (Figure 5).

The present results indicate that ATX, via its antioxidant properties, may prevent important deleterious effects of $\mathrm{A} \beta \mathrm{O}$ s on gene expression, which might be controlled at least in part by the calcineurin/NFAT pathway. Taken together, our results demonstrate the potential of ATX to prevent synaptotoxic effects of $\mathrm{A} \beta \mathrm{O}$ s in an in vitro model of $\mathrm{AD}$. Given the neuroprotective effects of ATX against different neurological disorders, the results presented here support the idea that daily consumption of ATX may be a beneficial strategy in human health management of $\mathrm{AD}$ and possibly of other neurological disorders as well.

\section{Conflict of Interests}

The authors declare that there is no conflict of interests regarding the publication of this paper.

\section{Acknowledgments}

Financial support was provided by FONDECYT 1150736, CORFO 13IDL2-18271, FONDECYT 1140545, FONDECYT 11140580, BNI (P-09-015F), and PMI-UVA1402. The authors thank Dr. Osvaldo Rubilar from BIOTEX S.A. for kindly providing ATX.

\section{References}

[1] C. Haass and D. J. Selkoe, "Soluble protein oligomers in neurodegeneration: lessons from the Alzheimer's amyloid $\beta$ peptide," Nature Reviews Molecular Cell Biology, vol. 8, no. 2, pp. 101-112, 2007.

[2] Y. Gong, L. Chang, K. L. Viola et al., "Alzheimer's diseaseaffected brain: presence of oligomeric $\mathrm{A} \beta$ ligands (ADDLs) suggests a molecular basis for reversible memory loss," Proceedings of the National Academy of Sciences of the United States of America, vol. 100, no. 18, pp. 10417-10422, 2003.

[3] L. Forny-Germano, N. M. Lyra e Silva, A. F. Batista et al., "Alzheimer's disease-like pathology induced by amyloidoligomers in nonhuman primates," The Journal of Neuroscience, vol. 34, no. 41, pp. 13629-13643, 2014.

[4] S. T. Ferreira, M. V. Lourenco, M. M. Oliveira, and F. G. De Felice, "Soluble amyloid- $\beta$ oligomers as synaptotoxins leading to cognitive impairment in Alzheimer's disease," Frontiers in Cellular Neuroscience, vol. 9, article 191, 2015.

[5] D. A. Butterfield, A. M. Swomley, and R. Sultana, "Amyloid $\beta$-peptide (1-42)-induced oxidative stress in alzheimer disease: importance in disease pathogenesis and progression," Antioxidants and Redox Signaling, vol. 19, no. 8, pp. 823-835, 2013.

[6] K. J. Barnham, C. L. Masters, and A. I. Bush, "Neurodegenerative diseases and oxidative stress," Nature Reviews Drug Discovery, vol. 3, no. 3, pp. 205-214, 2004. 
[7] P. B. Campos, B. S. Paulsen, and S. K. Rehen, "Accelerating neuronal aging in in vitro model brain disorders: a focus on reactive oxygen species," Frontiers in Aging Neuroscience, vol. 6, article 292, 2014.

[8] K. N. Green and F. M. LaFerla, "Linking calcium to $\mathrm{A} \beta$ and Alzheimer's disease," Neuron, vol. 59, no. 2, pp. 190-194, 2008.

[9] F. G. De Felice, P. T. Velasco, M. P. Lambert et al., "A $\beta$ oligomers induce neuronal oxidative stress through an $N$-methyl-Daspartate receptor-dependent mechanism that is blocked by the Alzheimer drug memantine," The Journal of Biological Chemistry, vol. 282, no. 15, pp. 11590-11601, 2007.

[10] A. C. Paula-Lima, J. Brito-Moreira, and S. T. Ferreira, "Deregulation of excitatory neurotransmission underlying synapse failure in Alzheimer's disease," Journal of Neurochemistry, vol. 126, no. 2, pp. 191-202, 2013.

[11] G. M. Shankar, B. L. Bloodgood, M. Townsend, D. M. Walsh, D. J. Selkoe, and B. L. Sabatini, "Natural oligomers of the Alzheimer amyloid- $\beta$ protein induce reversible synapse loss by modulating an NMDA-type glutamate receptor-dependent signaling pathway," Journal of Neuroscience, vol. 27, no. 11, pp. 2866-2875, 2007.

[12] M. P. Parsons and L. A. Raymond, "Extrasynaptic NMDA receptor involvement in central nervous system disorders," Neuron, vol. 82, no. 2, pp. 279-293, 2014.

[13] A. Sebollela, L. Freitas-Correa, F. F. Oliveira et al., "Amyloid- $\beta$ oligomers induce differential gene expression in adult human brain slices," The Journal of Biological Chemistry, vol. 287, no. 10, pp. 7436-7445, 2012.

[14] C. Barucker, A. Harmeier, J. Weiske et al., "Nuclear translocation uncovers the amyloid peptide a $\beta 42$ as a regulator of gene transcription," Journal of Biological Chemistry, vol. 289, no. 29, pp. 20182-20191, 2014.

[15] L. C. Reese and G. Taglialatela, "A role for calcineurin in Alzheimer's disease," Current Neuropharmacology, vol. 9, no. 4, pp. 685-692, 2011.

[16] H. Wu, H. Niu, A. Shao et al., "Astaxanthin as a potential neuroprotective agent for neurological diseases," Marine Drugs, vol. 13, no. 9, pp. 5750-5766, 2015.

[17] S. D. Rege, T. Geetha, T. L. Broderick, and J. R. Babu, "Resveratrol protects $\beta$ amyloid-induced oxidative damage and memory associated proteins in H19-7 hippocampal neuronal cells," Current Alzheimer Research, vol. 12, no. 2, pp. 147-156, 2015.

[18] M. Kurashige, E. Okimasu, M. Inoue, and K. Utsumi, "Inhibition of oxidative injury of biological membranes by astaxanthin," Physiological Chemistry and Physics and Medical NMR, vol. 22, no. 1, pp. 27-38, 1990.

[19] E. Hernández-Marin, A. Barbosa, and A. Martínez, "The metal cation chelating capacity of astaxanthin. Does this have any influence on antiradical activity?" Molecules, vol. 17, no. 1, pp. 1039-1054, 2012.

[20] M. O. M. Tso and T.-T. Lam, "Method of retarding and ameliorating central nervous system and eye damage," United States Patent US 5527533, 1996.

[21] N. Shimidzu, M. Goto, and W. Miki, "Carotenoids as singlet oxygen quenchers in marine organisms," Fisheries Science, vol. 62, no. 1, pp. 134-137, 1996.

[22] K. Nakagawa, T. Kiko, T. Miyazawa et al., "Antioxidant effect of astaxanthin on phospholipid peroxidation in human erythrocytes," British Journal of Nutrition, vol. 105, no. 11, pp. 1563-1571, 2011.
[23] H. Shen, C.-C. Kuo, J. Chou et al., "Astaxanthin reduces ischemic brain injury in adult rats," The FASEB Journal, vol. 23, no. 6, pp. 1958-1968, 2009.

[24] M. Ichida and T. Finkel, "Ras regulates NFAT3 activity in cardiac myocytes," The Journal of Biological Chemistry, vol. 276, no. 5, pp. 3524-3530, 2001.

[25] A. C. Paula-Lima, T. Adasme, C. Sanmartín et al., "Amyloid $\beta$ peptide oligomers stimulate RyR-mediated $\mathrm{Ca}^{2+}$ release inducing mitochondrial fragmentation in hippocampal neurons and prevent RyR-mediated dendritic spine remodeling produced by BDNF," Antioxidants \& Redox Signaling, vol. 14, no. 7, pp. 12091223, 2011.

[26] C. D. SanMartín, A. C. Paula-Lima, C. Hidalgo, and M. T. Núñez, "Sub-lethal levels of amyloid $\beta$-peptide oligomers decrease non-transferrin-bound iron uptake and do not potentiate iron toxicity in primary hippocampal neurons," BioMetals, vol. 25, no. 4, pp. 805-813, 2012.

[27] C. D. SanMartín, A. C. Paula-Lima, A. García et al., "Ryanodine receptor-mediated $\mathrm{Ca}^{2+}$ release underlies iron-induced mitochondrial fission and stimulates mitochondrial $\mathrm{Ca}^{2+}$ uptake in primary hippocampal neurons," Frontiers in Molecular Neuroscience, vol. 7, article 13, 2014.

[28] A. C. Paula-Lima, F. G. De Felice, J. Brito-Moreira, and S. T. Ferreira, "Activation of GABAA receptors by taurine and muscimol blocks the neurotoxicity of $\beta$-amyloid in rat hippocampal and cortical neurons," Neuropharmacology, vol. 49, no. 8, pp. 11401148, 2005.

[29] A. C. Paula-Lima, M. A. Tricerri, J. Brito-Moreira et al., "Human apolipoprotein A-I binds amyloid- $\beta$ and prevents $A \beta$-induced neurotoxicity," International Journal of Biochemistry and Cell Biology, vol. 41, no. 6, pp. 1361-1370, 2009.

[30] V. V. Belousov, A. F. Fradkov, K. A. Lukyanov et al., "Genetically encoded fluorescent indicator for intracellular hydrogen peroxide," Nature Methods, vol. 3, no. 4, pp. 281-286, 2006.

[31] M. W. Pfaffl, "A new mathematical model for relative quantification in real-time RT-PCR," Nucleic Acids Research, vol. 29, no. 9, article e45, 2001.

[32] Y. Lu, T. Xie, X.-X. He et al., "Astaxanthin rescues neuron loss and attenuates oxidative stress induced by amygdala kindling in adult rat hippocampus," Neuroscience Letters, vol. 597, pp. 4953, 2015.

[33] X. Zhou, F. Zhang, X. Hu et al., "Inhibition of inflammation by astaxanthin alleviates cognition deficits in diabetic mice," Physiology \& Behavior, vol. 151, pp. 412-420, 2015.

[34] B. J. Tabner, J. Mayes, and D. Allsop, "Hypothesis: soluble A $\beta$ oligomers in association with redox-active metal ions are the optimal generators of reactive oxygen species in Alzheimer's disease," International Journal of Alzheimer's Disease, vol. 2011, Article ID 546380, 6 pages, 2011.

[35] T. Ma, C. A. Hoeffer, H. Wong et al., "Amyloid $\beta$-induced impairments in hippocampal synaptic plasticity are rescued by decreasing mitochondrial superoxide," Journal of Neuroscience, vol. 31, no. 15, pp. 5589-5595, 2011.

[36] H. Bading, "Nuclear calcium signalling in the regulation of brain function," Nature Reviews Neuroscience, vol. 14, no. 9, pp. 593-608, 2013.

[37] P. L. Greer and M. E. Greenberg, "From synapse to nucleus: calcium-dependent gene transcription in the control of synapse development and function," Neuron, vol. 59, no. 6, pp. 846-860, 2008.

[38] M. Cavazzini, T. Bliss, and N. Emptage, " $\mathrm{Ca}^{2+}$ and synaptic plasticity," Cell Calcium, vol. 38, no. 3-4, pp. 355-367, 2005. 
[39] F. M. LaFerla, "Calcium dyshomeostasis and intracellular signalling in Alzheimer's disease," Nature Reviews Neuroscience, vol. 3, no. 11, pp. 862-872, 2002.

[40] N. Schwartz, A. Schohl, and E. S. Ruthazer, "Neural activity regulates synaptic properties and dendritic structure in vivo through calcineurin/NFAT signaling," Neuron, vol. 62, no. 5, pp. 655-669, 2009.

[41] J. D. Ulrich, M.-S. Kim, P. R. Houlihan et al., "Distinct activation properties of the nuclear factor of activated T-cells (NFAT) isoforms NFATc3 and NFATc4 in neurons," The Journal of Biological Chemistry, vol. 287, no. 45, pp. 37594-37609, 2012.

[42] H.-Y. Wu, E. Hudry, T. Hashimoto et al., "Amyloid $\beta$ induces the morphological neurodegenerative triad of spine loss, dendritic simplification, and neuritic dystrophies through calcineurin activation," Journal of Neuroscience, vol. 30, no. 7, pp. 26362649, 2010.

[43] E. Hudry, H.-Y. Wu, M. Arbel-Ornath et al., "Inhibition of the NFAT pathway alleviates amyloid beta neurotoxicity in a mouse model of Alzheimer's disease," The Journal of Neuroscience, vol. 32, no. 9, pp. 3176-3192, 2012.

[44] H. M. Abdul, M. A. Sama, J. L. Furman et al., "Cognitive decline in Alzheimer's disease is associated with selective changes in Calcineurin/NFAT signaling," Journal of Neuroscience, vol. 29, no. 41, pp. 12957-12969, 2009.

[45] H. M. Abdul, J. L. Furman, M. A. Sama, D. M. Mathis, and C. M. Norris, "NFATs and Alzheimer's disease," Molecular and Cellular Pharmacology, vol. 2, no. 1, pp. 7-14, 2010.

[46] T. Adasme, P. Haeger, A. C. Paula-Lima et al., "Involvement of ryanodine receptors in neurotrophin-induced hippocampal synaptic plasticity and spatial memory formation," Proceedings of the National Academy of Sciences of the United States of America, vol. 108, no. 7, pp. 3029-3034, 2011.

[47] D. Baglietto-Vargas, Y. Chen, D. Suh et al., "Short-term modern life-like stress exacerbates $\mathrm{A} \beta$-pathology and synapse loss in 3xTg-AD mice," Journal of Neurochemistry, vol. 134, no. 5, pp. 915-926, 2015.

[48] C. Ballard, S. Gauthier, A. Corbett, C. Brayne, D. Aarsland, and E. Jones, "Alzheimer's disease," The Lancet, vol. 377, no. 9770, pp. 1019-1031, 2011.

[49] C. Reitz and R. Mayeux, "Alzheimer disease: epidemiology, diagnostic criteria, risk factors and biomarkers," Biochemical Pharmacology, vol. 88, no. 4, pp. 640-651, 2014.

[50] F. Di Domenico, E. Barone, M. Perluigi, and D. A. Butterfield, "Strategy to reduce free radical species in Alzheimer's disease: an update of selected antioxidants," Expert Review of Neurotherapeutics, vol. 15, no. 1, pp. 19-40, 2015.

[51] C. R. Giordano, L. J. Terlecky, A. Bollig-Fischer, P. A. Walton, and S. R. Terlecky, "Amyloid- $\beta$ neuroprotection mediated by a targeted antioxidant," Scientific Reports, vol. 4, article 4983, 2014.

[52] C. D. SanMartin, T. Adasme, C. Hidalgo, and A. C. PaulaLima, "The antioxidant N-acetylcysteine prevents the mitochondrial fragmentation induced by soluble amyloid- $\beta$ peptide oligomers," Neurodegenerative Diseases, vol. 10, no. 1-4, pp. 3437, 2012.

[53] B. P. Hubbard and D. A. Sinclair, "Small molecule SIRT1 activators for the treatment of aging and age-related diseases," Trends in Pharmacological Sciences, vol. 35, no. 3, pp. 146-154, 2014.

[54] L. Shen and H.-F. Ji, "Vitamin E: supplement versus diet in neurodegenerative diseases," Trends in Molecular Medicine, vol. 18, no. 8, pp. 443-445, 2012.
[55] T. Persson, B. O. Popescu, and A. Cedazo-Minguez, "Oxidative stress in Alzheimer's disease: why did antioxidant therapy fail?" Oxidative Medicine and Cellular Longevity, vol. 2014, Article ID 427318, 11 pages, 2014.

[56] M. Gammone, G. Riccioni, and N. D'Orazio, "Marine carotenoids against oxidative stress: effects on human health," Marine Drugs, vol. 13, no. 10, pp. 6226-6246, 2015.

[57] S. Dodd, O. Dean, D. L. Copolov, G. S. Malhi, and M. Berk, "N-acetylcysteine for antioxidant therapy: pharmacology and clinical utility," Expert Opinion on Biological Therapy, vol. 8, no. 12, pp. 1955-1962, 2008.

[58] O. Dean, F. Giorlando, and M. Berk, "N-acetylcysteine in psychiatry: current therapeutic evidence and potential mechanisms of action," Journal of Psychiatry and Neuroscience, vol. 36, no. 2, pp. 78-86, 2011.

[59] R. Bull, J. P. Finkelstein, A. Humeres, M. I. Behrens, and C. Hidalgo, "Effects of ATP, $\mathrm{Mg}^{2+}$, and redox agents on the $\mathrm{Ca}^{2+}$ dependence of RyR channels from rat brain cortex," American Journal of Physiology-Cell Physiology, vol. 293, no. 1, pp. C162C171, 2007.

[60] Q. Huang, C. D. Aluise, G. Joshi et al., "Potential in vivo amelioration by N-Acetyl-L-cysteine of oxidative stress in brain in human double mutant APP/PS-1 knock-in mice: toward therapeutic modulation of mild cognitive impairment," Journal of Neuroscience Research, vol. 88, no. 12, pp. 2618-2629, 2010.

[61] S. Franceschelli, M. Pesce, A. Ferrone et al., "Astaxanthin treatment confers protection against oxidative stress in U937 cells stimulated with lipopolysaccharide reducing $\mathrm{O}_{2}$-production," PLoS ONE, vol. 9, no. 2, Article ID e88359, 2014.

[62] E. Rodrigues, L. R. B. Mariutti, and A. Z. Mercadante, "Scavenging capacity of marine carotenoids against reactive oxygen and nitrogen species in a membrane-mimicking system," Marine Drugs, vol. 10, no. 8, pp. 1784-1798, 2012.

[63] Y. Ni, M. Nagashimada, F. Zhuge et al., "Astaxanthin prevents and reverses diet-induced insulin resistance and steatohepatitis in mice: a comparison with vitamin E," Scientific Reports, vol. 5, Article ID 17192, 2015.

[64] X. Wen, A. Huang, J. Hu et al., "Neuroprotective effect of astaxanthin against glutamate-induced cytotoxicity in HT22 cells: involvement of the Akt/GSK-3 $\beta$ pathway," Neuroscience, vol. 303, pp. 558-568, 2015.

[65] C. L. L. Saw, A. Y. Yang, Y. Guo, and A.-N. T. Kong, "Astaxanthin and omega-3 fatty acids individually and in combination protect against oxidative stress via the Nrf2-ARE pathway," Food and Chemical Toxicology, vol. 62, pp. 869-875, 2013.

[66] R. Brigelius-Flohé and L. Flohé, "Basic principles and emerging concepts in the redox control of transcription factors," Antioxidants and Redox Signaling, vol. 15, no. 8, pp. 2335-2381, 2011.

[67] C. Li, P. Hossieny, B. J. Wu, A. Qawasmeh, K. Beck, and R. Stocker, "Pharmacologic induction of heme oxygenase-1," Antioxidants and Redox Signaling, vol. 9, no. 12, pp. 2227-2239, 2007.

[68] M. M. Al-Amin, S. Akhter, A. T. Hasan et al., "The antioxidant effect of astaxanthin is higher in young mice than aged: a region specific study on brain," Metabolic Brain Disease, vol. 30, no. 5, pp. 1237-1246, 2015.

[69] J.-P. Yuan, J. Peng, K. Yin, and J.-H. Wang, "Potential healthpromoting effects of astaxanthin: a high-value carotenoid mostly from microalgae," Molecular Nutrition and Food Research, vol. 55, no. 1, pp. 150-165, 2011.

[70] C.-H. Chang, C.-Y. Chen, J.-Y. Chiou, R. Y. Peng, and C.H. Peng, "Astaxanthine secured apoptotic death of PC12 cells 
induced by $\beta$-amyloid peptide 25-35: its molecular action targets," Journal of Medicinal Food, vol. 13, no. 3, pp. 548-556, 2010.

[71] H.-Q. Wang, X.-B. Sun, Y.-X. Xu, H. Zhao, Q.-Y. Zhu, and C.Q. Zhu, "Astaxanthin upregulates heme oxygenase-1 expression through ERK1/2 pathway and its protective effect against beta-amyloid-induced cytotoxicity in SH-SY5Y cells," Brain Research, vol. 1360, pp. 159-167, 2010.

[72] I. Bezprozvanny and M. P. Mattson, "Neuronal calcium mishandling and the pathogenesis of Alzheimer's disease," Trends in Neurosciences, vol. 31, no. 9, pp. 454-463, 2008.

[73] M. J. Berridge, "Calcium hypothesis of Alzheimer's disease," Pflugers Archiv European Journal of Physiology, vol. 459, no. 3, pp. 441-449, 2010.

[74] C. Hidalgo, "Cross talk between $\mathrm{Ca}^{2+}$ and redox signalling cascades in muscle and neurons through the combined activation of ryanodine receptors $/ \mathrm{Ca}^{2+}$ release channels," Philosophical Transactions of the Royal Society B: Biological Sciences, vol. 360, no. 1464, pp. 2237-2246, 2005.

[75] J. J. Marengo, C. Hidalgo, and R. Bull, "Sulfhydryl oxidation modifies the calcium dependence of ryanodine-sensitive calcium channels of excitable cells," Biophysical Journal, vol. 74, no. 3, pp. 1263-1277, 1998.

[76] M. Kelliher, J. Fastbom, R. F. Cowburn et al., "Alterations in the ryanodine receptor calcium release channel correlate with Alzheimer's disease neurofibrillary and $\beta$-amyloid pathologies," Neuroscience, vol. 92, no. 2, pp. 499-513, 1999.

[77] A. C. Paula-Lima, T. Adasme, and C. Hidalgo, "Contribution of $\mathrm{Ca}^{2+}$ release channels to hippocampal synaptic plasticity and spatial memory: potential redox modulation," Antioxidants \& Redox Signaling, vol. 21, no. 6, pp. 892-914, 2014.

[78] A. Mukherjee and C. Soto, "Role of calcineurin in neurodegeneration produced by misfolded proteins and endoplasmic reticulum stress," Current Opinion in Cell Biology, vol. 23, no. 2, pp. 223-230, 2011.

[79] F. Liu, I. Iqbal-Grundke, K. Iqbal, Y. Oda, K. Tomizawa, and C.-X. Gong, "Truncation and activation of calcineurin A by calpain I in Alzheimer disease brain," The Journal of Biological Chemistry, vol. 280, no. 45, pp. 37755-37762, 2005. 

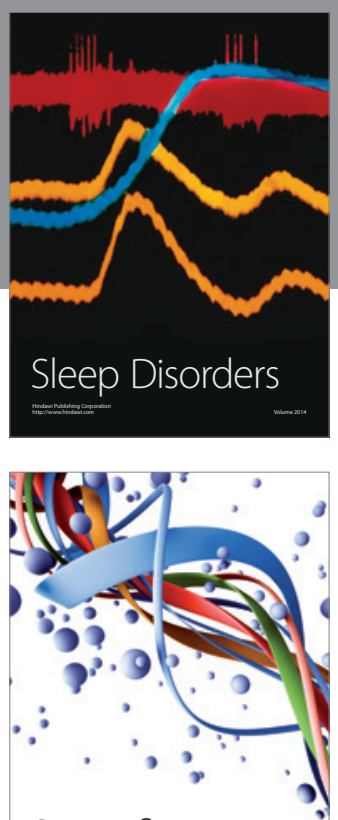

Scientifica
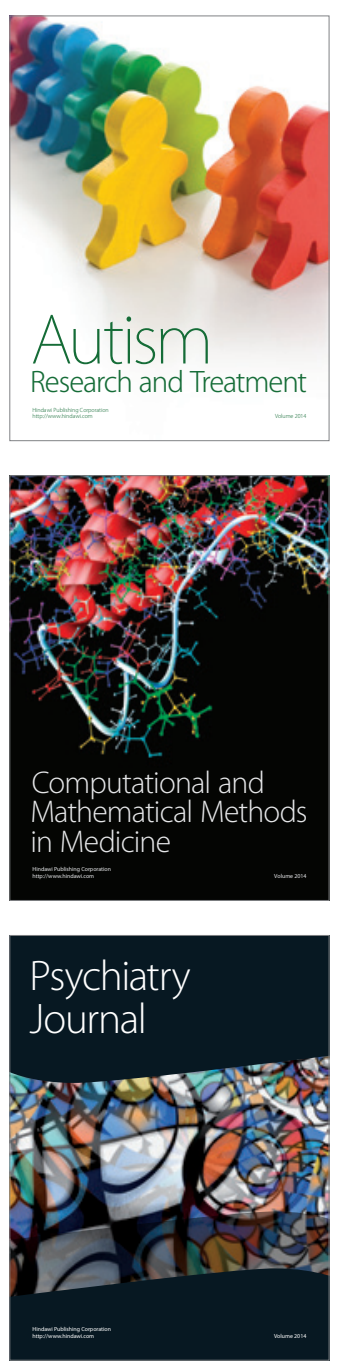
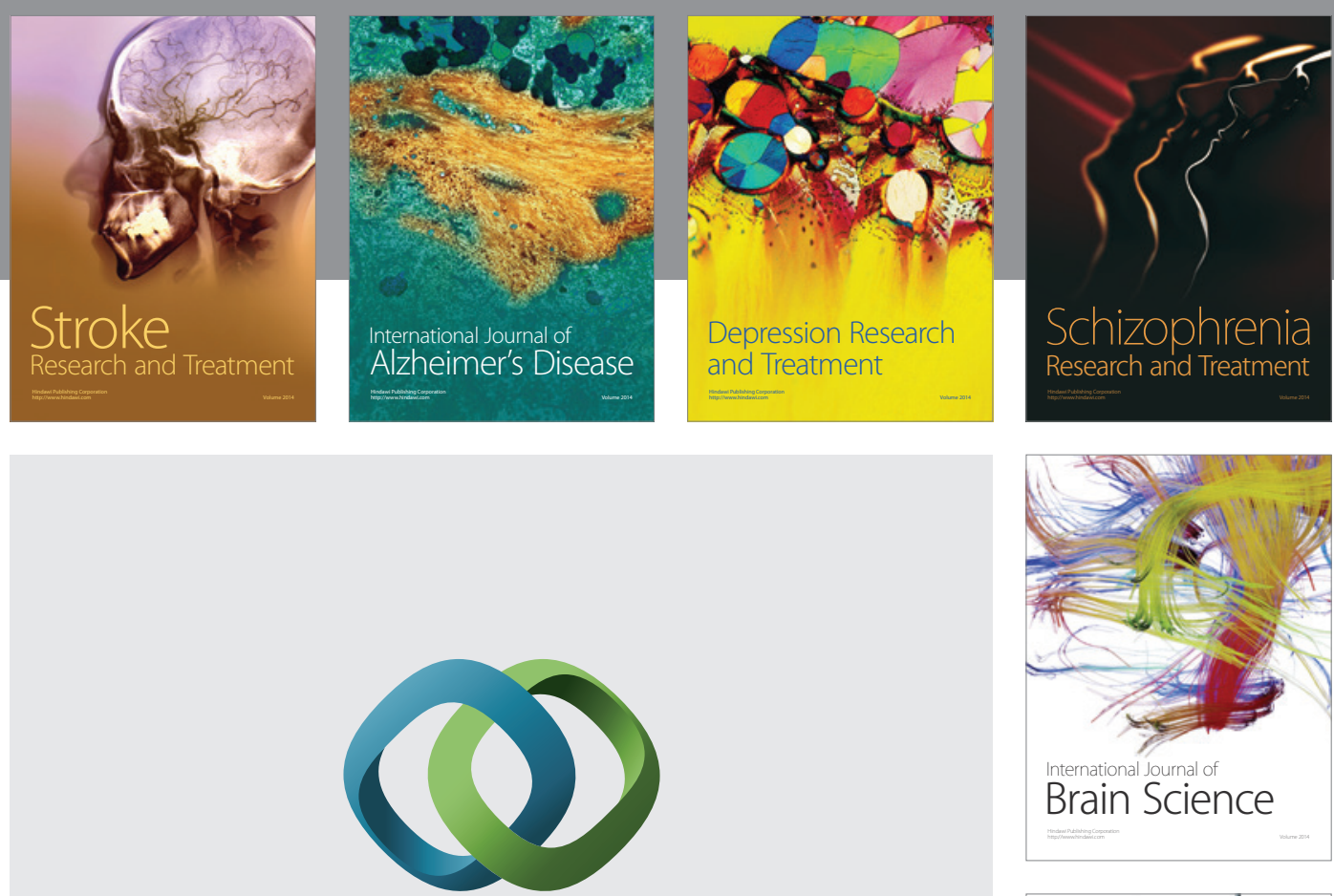

\section{Hindawi}

Submit your manuscripts at

http://www.hindawi.com
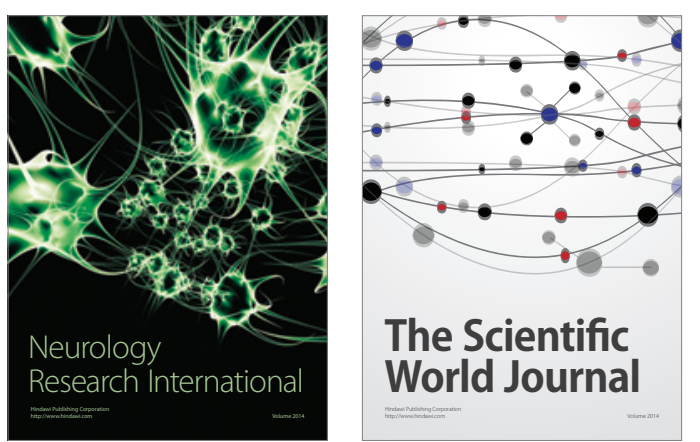

The Scientific World Journal

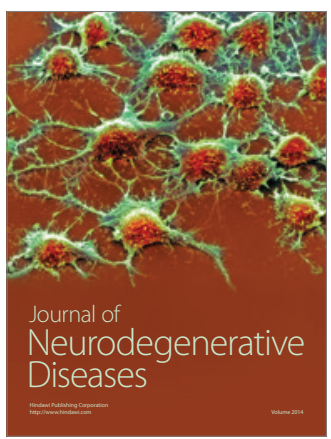

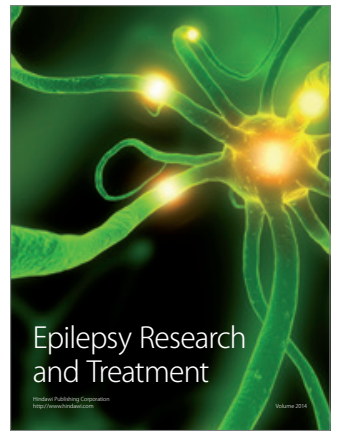

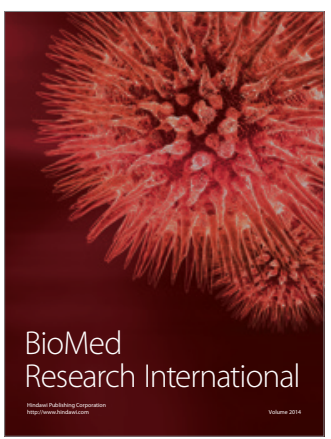

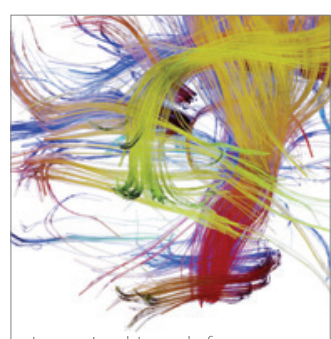

Brain Science

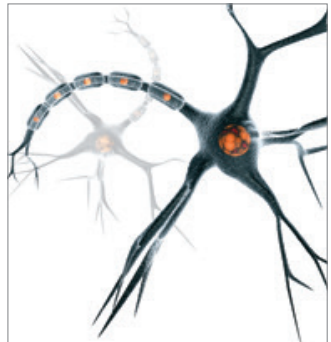

Neural Plasticity
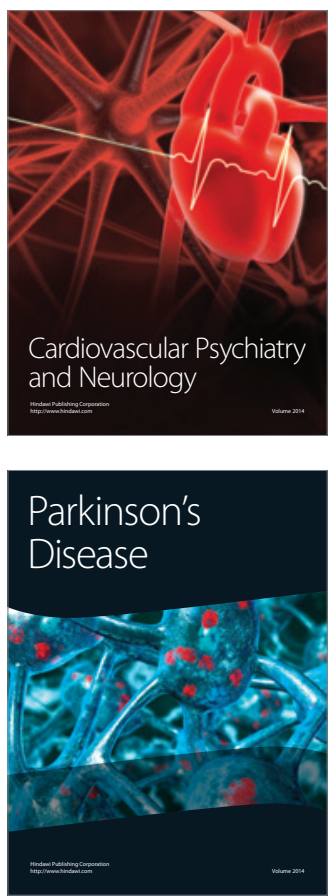